\title{
Multimodal strategic approach in the clinical assessment of malingering - keeping an eye on truth!!!
}

\author{
Tanushree V ${ }^{1, *}$, Vinuta Mohan Kulkarni ${ }^{2}$, Subramanya Kota $^{3}$, Bhavya Reddy ${ }^{4}$ \\ 1,3 Assisstant Professor, ${ }^{2}$ Junior Resident, ${ }^{4}$ Senior Resident, Dept. of Ophthalmology, BMCRI, Minto Eye Hospital, Bangalore, Karnataka, \\ India
}

*Corresponding Author: Tanushree V

Email: tanushree19686@gmail.com

\begin{abstract}
Purpose: To evaluate patients who present with ophthalmic problems with no discernible organic cause and detect malingering in such cases.

Materials and Methods: 175 patients reporting to the Ophthalmology outpatient department from January 2017 to January 2018 were included. Patients were examined by various tests in order to document the proof for the reported visual loss. Objective prism tests, Special test cards, Visually evoked potential, Electroretinogram, Visual field analysis, various non visual tasks, Stereopsis testing ,Refraction and behavior of the patient with the clinician were assessed. Data collected and analysed with descriptive statistics.

Results: In 175 patients examined, 92 patients (52.6\%) were proved to be malingering by above mentioned tests which is statistically significant.

Conclusion: Ocular malingering should be suspected when even with the most thorough ocular examination does not reveal a plausible cause for the reported visual loss and exposes the deception behind claims of visual loss in malingerers.
\end{abstract}

Keywords: Ocular malingering, Functional visual loss, Disability certificate.

\section{Introduction}

Malingering or functional visual loss refers to Functional visual loss or malingering refers to a decrease in visual acuity or loss of visual field with no underlying physiologic or organic basis. It is willful exaggeration of symptoms and litigation involves monetary compensation or disability status. This includes total of $1-5 \%$ of the referrals to ophthalmologists. This is highest in the age group of 1120 years old patients with a male predominance. ${ }^{1,2}$ This often involves some benefit for the candidate, either monetary or non - monetary such as getting jobs in Government settings reserved for disabled people. It is in the ophthalmologists hand to explore the truth which will prevent benefit going to wrong person. This will help in giving opportunity to more deserving candidate for such benefit. Not many studies are found in the literature about the presentation in malingering and assessment in such people. This study intends to detect malingering in patients presenting to our tertiary care center and demonstrate multimodal strategy in the clinical assessment in malingering.

\section{Materials and Methods}

A hospital based prospective study conducted on 175 patients reporting to the Ophthalmology out patient department from January 2017 to January 2018.175 patients who attended our OPD for disability certificate to claim job in in various departments under disability reservation were included in the study. All the patients underwent detailed ocular examination, including visual acuity testing, refraction under cycloplegia and with autorefractometer, detailed slit lamp examination to look for anterior segment pathology that can explain the reason for visual loss claimed. Detailed posterior segment evaluation including fundus examination done, Bscan ultrasonography, Optical coherence tomography in required cases to find out pathology that can explain the reason for visual loss claimed by the patient. When thorough examination did not reveal a plausible cause for visual loss, malingering was considered as a diagnosis of exclusion.

All the patients underwent psychological approach to detect malingering. Psychological approach to detect malingering was done for all the candidates. This included observing the reaction of the patient during examination such as disgusted and aggressive behaviour, the desire of non co-operating or overplaying his part.

Further patients underwent various tests, based on the visual acuity claimed by the patients. Patients were categorised based on the visual acuity claimed by the candidate. According to the guidelines given by Ministry of Social justice and employement, Gazzete of India, patient with visual acuity of less than $6 / 60$ in worse eye can claim Government job under disability reservation. So we divided the patients based on the visual acuity claimed by the candidate and following tests done to detect malingering.

Test Approach

\begin{tabular}{|l|c|c|}
\hline PL negative & $\begin{array}{c}\text { PL + ve / HM } \\
\text { +ve }\end{array}$ & PL + VE to $<\mathbf{6 / 6 0}$ \\
\hline Prisms test & ERG & $\begin{array}{c}\text { Visual acuity by } \\
\text { reducing distance } \\
\text { to 4mtrs }\end{array}$ \\
\hline Refraction & VEP & Smart charts \\
\hline Menace reflex & & Refraction \\
\hline OKN reflex & & Visual fields \\
\hline ERG & & \\
\hline VEP & & \\
\hline
\end{tabular}


Based on above tests, malingering was detected and malingering detection by each test was noted. Data collected and tabulated. Data analysed using suitable descriptive statistics.

\section{Results}

Out of 175 candidates, 117 were males and 68 were females. (Table 1) 58 candidates claimed to have no perception of light and 117 candidates vision less than 6/60. (Table 2)

Among 58 candidates claiming PL negative, 24 candidates were found to malinger by various tests (Table 3). Among 117 candidates claiming PL positive to 6/60, 68 were found to malinger by objective tests in varying percentages (Table 4).

Out of 175 candidates, $92(52.57 \%)$ were found to be malingering. Remaining candidates were found to have amblyopia, pathological myopia, Stargards disease, retinitis pigmentosa in varying percentages. (Table 5)

Table 1: Gender distribution

\begin{tabular}{|l|c|c|}
\hline \multicolumn{1}{|c|}{ Sex } & No & \% \\
\hline Males & 117 & 66.9 \\
\hline Females & 58 & 33.2 \\
\hline
\end{tabular}

Table 2: Age distribution

\begin{tabular}{|l|c|c|}
\hline \multicolumn{1}{|c|}{ Visual Acuity Claimed } & No & \% \\
\hline PL Negative & 58 & 33.1 \\
\hline PL Positive $-<6 / 60$ & 117 & 66.9 \\
\hline
\end{tabular}

Table 3: Objective tests done to detect malingeringing

\begin{tabular}{|l|c|c|}
\hline Test & No & \% \\
\hline Prism test & 18 & 75 \\
\hline Menace reflex & 21 & 87.5 \\
\hline OKN Tests & 21 & 87.5 \\
\hline Refraction & 15 & 62.5 \\
\hline ERG & 24 & 100 \\
\hline VEP & 24 & 100 \\
\hline
\end{tabular}

Table 4: Objective tests done to detect malingeringing

\begin{tabular}{|l|c|c|}
\hline \multicolumn{1}{|c|}{ Test } & No & \% \\
\hline Visual testing using smart charts & 9 & 13.2 \\
\hline Visual testing at 4mtrs & 22 & 32.4 \\
\hline Visual field testing & 8 & 11.8 \\
\hline Refraction & 21 & 30.9 \\
\hline
\end{tabular}

Table 5: Causes of vision loss

\begin{tabular}{|l|c|c|}
\hline Cause of Vision Loss & No & \% \\
\hline Retinitis Pigmentosa & 14 & 8 \\
\hline Stargards disease & 12 & 6.8 \\
\hline Macular dystrophy & 2 & 1.14 \\
\hline Pathological myopia & 9 & 5.14 \\
\hline Amblyopia & 7 & 4 \\
\hline Pthisis bulbi & 26 & 14.9 \\
\hline Cone dystrophy & 5 & 2.86 \\
\hline Optic atrophy & 8 & 4.57 \\
\hline Malingering & 92 & 52.6 \\
\hline
\end{tabular}

\section{Discussion}

Malingering is to mislead wilfully in regard to the existence of a disease in order to gain a desired end. ${ }^{3}$ When detailed examination does not reveal the plausible cause for visual loss and extent of visual loss, ophthalmologist should suspect ocular malingering.

A malingerer usually complains of defective vision which may be divided into three classes: (1) total blindness in one eye, (2) partial blindness in one eye, (3) total or partial blindness in both eyes.

Various tests can be done detect malingering. Before doing any tests, patients should be evaluated as a whole and behaviour of the patient should be looked for. Psychological approach of assessing patients behaviour can detect malingering in all the patients. ${ }^{4}$ Malingering should be suspected in patients who are aggressive while testing, non co operative, overplaying while being examined.

Various tests for detecting malingering have been explained in the literature. This is based on the visual acuity claimed by the patient. This tests include.

Menace Reflex: examiner presents visual threats suddenly, the examiner can also suddenly drop an object to see if a patient will reflexively react.

Optokinetic Nystagmus Test: usually induces jerk nystagmus in patient with at least 20/400 vision.

Refraction: Detailed refraction, under cycloplegia can detect malingering when retinoscopy is not showing results that can explain the extent of visual loss.

Prism Tests:

Base-out Prism Test: A 10-prism diopter lens placed baseout in front of one eye should normally elicit a conjugate movement. A true loss of monocular vision will not result in conjugate movement when the prism is placed over the affected eye.

Vertical prism dissociation test: A 4-prism diopter lens is placed base-down in front of the good/unaffected eye. A $20 / 20$ of snellens is projected. If the patient is able to see two letters of equal clarity, it establishes good vision in the affected eye.

Visual acuity by reducing the distance of testing: Evaluate a patient's ability to read the Snellen chart at $6 \mathrm{mtrs}$ and then at $4 \mathrm{mtrs}$ feet. The patient should be able to read letters half the size of the letters read at the full distance. A patient with functional visual loss will often not admit to being able to read the smaller optotypes regardless of the proximity to the target.

Smart Charts: This includes testing with special optotypes. The distances of spaces between optotypes and their length are same but visual equivalents are different. This can detect malingering.

Electroencephalography: If changes in basal occipital rhythm recordings are observed, if perception of light is present.

Pattern visually evoked potentials: Evaluates afferent visual pathway dysfunctions including the macula and the optic nerve. In case of unilateral blindness, asymmetrical recordings of two eyes are seen. Normal PVEP and ERG is not compatible with visual acuity less than 6/60. Pattern 
VEP recordings can also quantify the visual acuity and help in detecting malingering. .,7 $^{6,7}$

Visual Fields: Excessive false negatives and gaze tracking can help in detecting malingering. Crossing isopters or a visual field that remains the same size regardless of the size or brightness of the test stimulus points towards malingering. ${ }^{8,9}$

Various other tests can be done based on the visual acuity claimed by the patient. Following table narrates the various tests that can be done to detect malingering (Fig. 1)
Apart from the tests, sensitivity of the situation should be understood by the clinician. Avoiding the relative of the patient while examining the patient, asking for the socio economic background of the patient, Hospitalisation and observation of the patient behavior can also help in detecting malingering in extreme cases.

Malingering can cause problem to the clinicians, as issuing of false certificate can cause legal problems and administrative problems. This also causes loss to the society and Government, as the deserving candidates will loose opportunity when malingerers claim jobs in such category.

\begin{tabular}{|c|c|c|}
\hline Bilateral blindness & Monocular bilindness or visual impalment & Bilateral visual impalment \\
\hline $\begin{array}{l}\text { 1. Testing of reflexes } \\
\text { - Observation of behavior } \\
\text { - Blink reflex } \\
\text { - Prisms: fixation movements } \\
\text { - OKN } \\
\text { - Mirror-induced pursuit } \\
\text { movements }\end{array}$ & $\begin{array}{l}\text { 1. Testing of reflexes } \\
\text { - Pupillary reactions: } \\
\text { relative afferent pupillary defect } \\
\text { - Convergence test } \\
\text { - Refixation movement when covering } \\
\text { the healthy eye }\end{array}$ & $\begin{array}{l}\text { 1. Deception regarding the sizes of optotypes } \\
\text { - Use of constant angular sizes of optotypes } \\
\text { at varying distances } \\
\text { - Testing with single optotypes, allowing } \\
\text { no comparisons to other characters } \\
\text { - Near acuities with optical magnification }\end{array}$ \\
\hline $\begin{array}{l}\text { - Fixation star of direct } \\
\text { ophthalmoscope } \\
\text { - Pupillary light reactions } \\
\text { 2. Deception } \\
\text { - Tasks of coordination that }\end{array}$ & $\begin{array}{l}\text { 2. Binocular Tests } \\
\text { - Prisms } \\
\text { - Stereoscuity } \\
\text { - Confusion test (polarized tests, } \\
\text { red-green glasses, etc) }\end{array}$ & $\begin{array}{l}\text { 2. Tests of central vision by other methods } \\
\text { - Central threshold sensitivity at the perimeter } \\
\text { - Preferential-looking acuity } \\
\text { - Fixation } \\
\text { - Laser interferometry } \\
\text { - Probability of seeing }\end{array}$ \\
\hline $\begin{array}{l}\text { require no visual function } \\
\text { - Saccades on command } \\
\text { combined with index finger } \\
\text { movements } \\
\text { 3. Objective testing methods } \\
\text { - VEP, ERG }\end{array}$ & $\begin{array}{l}\text { 3. Testing central visual functions } \\
\text { by other methods } \\
\text { - Central thresholds at the perimeter } \\
\text { - Preferential looking acuity } \\
\text { - Fixation } \\
\text { - Laser interferometry }\end{array}$ & $\begin{array}{l}\text { 3. Objective methods } \\
\text { - Acuity VEP } \\
\text { - Multifocal ERG } \\
\text { - OKN (quantitative) } \\
\text { - Psychogalvanic reflexes }\end{array}$ \\
\hline
\end{tabular}

Fig. 1

\section{Conclusion}

Malingering being diagnosis of exclusion, needs thorough examination and detailed work up. This proves that blindness may not just be inability to see, but can also be desire not to see. Appropriate tests for such cases can reduce expenditure by avoiding expensive investigations. Clinicians by detecting malingering can render better service to the society and Government.

\section{References}

1. Keltner JL, MayWN, Johnson CA, Post RB. The California syndrome. Functional visual complaints with potential economic impact. 1985;92(3):427-435.

2. Gandhi R, Amula GM. Malingering in Ophthalmology. E Medicine specialties. Ophthalmology Unclassified disorders. Update Sep. 2, 2009.

3. DukeElder: Text Book of ophthal mology (1949) ol. 4, Henry Kimp ton, London.

4. Singhal N C. Hysterical b lindness versus malingering. Indian J Ophthalmol. 1972;20:173-178.

5. Civelekler M, Halili I, Gündogan FC, Sobac G. Retinal nerve fiber layer thickness analysis in suspected malingerers with optic disc temporal pallor. Indian J Ophthalmol. 2009;57(5):365-370.

6. Weinstein GW, Odom JV, Cavender S. Visually evoked potentials and electroretinography in neurologic evaluation. Neurol Clin. 1991;9(1):225-242.

7. Renner AB, Kellner U, Tillack H, Kraus H, Foerster MH. Recording of both VEP and multifocal ERG for evaluation of unexplained visual loss. Doc Ophthalmol. 2005;111(3):149157.
8. Miller NR. Funct Neuro-ophthalmol. 2011;102:493-513.

9. Bruce BB, Newman NJ. Functional Visual Loss. 2010;28(3):789-802.

How to cite this article: Tanushree V, Kulkarni V. M, Kota S, Reddy B. Multimodal strategic approach in the clinical assessment of malingering - keeping an eye on truth!!!. Int J Ocul Oncol Oculoplasty. 2018;4(4):166-168. 